International Journal of Kurdish Studies

(ISSN:2149-2751)

2 (3), pp. $165-178$

http://www.ijoks.com

\title{
On the Reduplication in Kurdish language
}

\section{Manijeh Mirmokri ${ }^{1}$}

Received: June 11, 2016
Shahla Seifori ${ }^{2}$

Reviewed: June 24, 2016

Accepted: July 22, 2016

\begin{abstract}
Reduplicated words are a fascinating, and fun aspect of language. In many languages (nearly 85\%) reduplication has been observed. Reduplication, as Charles Kauffman (2015) points out is a morphological process that through doubling a morpheme enhances, emphasizes, amplifies, enlarges, diminishes, adds number or changes verb tense - to bring about significant meaning changes or shades of meaning. In general, there are two basic forms - full reduplication and partial reduplication that each of them includes several forms. In this research, our purpose is identifying and introducing a variety of reduplication patterns in Kurdish language. For this purpose we explored more than 700 samples of reduplications in Kurdish language and categorized them in several sets. We noticed that frequentative, increased action, and plural action as the most common semantic categories marked by reduplication in the samples. The studies show that this morphological process especially partial type causes some changes in the meaning of resulting combinations. What is added to the reduplicant (base or root), in most cases, is meaningless. It also seems this kind of words especially partial ones are used in informal language and an ironic meaning is inferred by them.
\end{abstract}

Keywords: reduplication, morphological, full, partial, frequency

Recommended citation:

Mirmokri, M. \& Seifori, S. (2016). On the Reduplication in Kurdish language. International Journal of Kurdish Studies 2 (3), 165- 178.

\footnotetext{
${ }^{1}$ Phd Student of General Linguistics in Sanandaj Azad University ( manijeh.mirmokri@ gmail.com)

${ }^{2}$ Phd Student of General Linguistics in Sanandaj Azad University (seifourish@yahoo.com)
} 


\section{INTRODUCTION}

Sometimes word formation does not consciously occur. However, we can recognize its processes and categorize the patterns correctly. Among processes such as derivation, compounding, reduplication, clipping, abbreviation making, acronym making, novel wordcoining that were pointed out by Shaghaghi (2012: 85-112), except derivation and compounding, other processes have received less attention. Among these processes, derivation is very similar to reduplication process whereas it is different with normal affixation.

Reduplication is a process of word formation that is done in reply to the verbal speakers' needs in order to make suitable words for expressing concept, in a given moment, from the analogy. It should be noted that reduplication (repeat) is sometimes full of ambiguity and it should be different from other grammatical phenomena that are similar to it. A number of word pairs are not included in the context of definitions that are expressed for reduplication. In order to recognize this process from other grammatical categories, present definitions should be carefully reviewed.

Inkelas (2006) argued that there is a fundamental difference related to typological between the proliferation of phoneme and morphological doubling and he considered a dual theory for reduplication process. It seems that there are differences among linguists and researchers that work on iteration process in different languages about selecting term of reduplication or doubling or reorganization for naming the process. Kauffman (2015) argues it includes waste repeat because if duplication means doubling, so what is a requirement for using prefix "re" in the beginning of the word? Why not applying the same as duplication or doubling? But despite the controversy against redundancy of prefix "re" and term of duplication that imply the same meaning, term of reduplication is widely accepted as a normal name in linguistics. Tkaczyk (2005) used a more neutral term for this phenomenon. He called this process as simulation and expressed that language item can duplicate itself or it can be duplicated. Kurdish researchers also were helped by two words term (binary) or pair words for this kind of constructs.

It is tried in this article to refer to background literature of non-Kurdish and also research related to Kurdish language in this field and then different patterns of duplications in Kurdish language are introduced and different aspects that can be addressed in Kurdish language regarding this process are pointed out.

\section{Reduplication}

Lai points out reduplication refers to the process whereby a whole construction in question or part of the construction in question is reiterated to form a new construction - the former being a total reduplication whereas the latter a partial reduplication (Lai, 2006: 483484). Basic element in reduplication process is called reduplicant that belongs to one of different grammatical categories (verb, noun, adjective, adverb, etc.). Reduplication can be associated with concepts such as strengthening and weakening which are contradictory. Novotna (2000:57) stated: detecting incomplete duplicate (section or syllable of 
a word) from full iteration (total morpheme) is possible and in addition there are multiple reduplications that three identical elements are going after the other - that is not our subject he considered iteration as an absolutely grammatical phenomenon that meet the morphological- syntactic goals and also it is raised in the level of terminology and word formation.

\section{Reduplication process in non- Kurdish researches:}

As Mattes (2014:12-13) has mentioned Pott (1862) did studies on reduplication in American, African and Asian languages; inspired by him, some greater attention was given to a much smaller, but comparable typological study on reduplications by Brandstetter (1917). Then, Grein (1862), Wood (1895), Brugman (1912,13), Kastein (1927) paid specially great attention to reduplicated preterit. Kocher (1921) worked on French and Italian, and Gonda (1950) was the first researcher went into a detailed description in a non-European language family, namely Indonesian, but also referred to other languages. Examples of language specific typologies on reduplication include Hestermann (1915) on Serer Sine (srr), Haeberlin (1918) on Salish dialects, Blake (1917) and Lopez (1950) on Tagalog, Haas (1942) onThai (tha), Anagbogu (1955) on Igbo (ibo) and many more have researched about Reduplication. There are so many pervious researches on reduplication in different languages plus to what he brought in his dissertation.

Kauffman (2015) points out types of reduplication: Full, Partial, Baby-talk, Rhyming, Ablaut, Onomatopoeia, name doubling, Sha- Reduplication with examples from different languages and shows uses of Reduplication: Forming plurals, verb tenses, intensity, amplification, enhancement- specificity, diversity and collectivity, similarity, playfulness, aimlessness and vagueness, reciprocity and statements on life.

Khanjan and Alinezhad (2010) have researched about three types of Full reduplication in Persian: pure, medial, and final full reduplication. They have done the investigations about reduplication processes in the framework of Morphological Doubling Theory (MDT) (Inkelas \& Zoll 2005). Among the most important findings of this study, the following are worth mentioning: patterns of Persian full reduplication are not limited to the morpheme or word level but, rather, they cover a range of linguistic expressions from a single word to an entire syntactic construction; the semantic feature bundle of the output of Persian full reduplication may vary on a relative continuum ranging from iconic to totally idiomatic/metaphorical meanings and, in some cases, it is affected by contextual parameters; and finally, patterns of Persian full reduplication are sometimes of stylistic significance and are subject to certain register restrictions (Khanjan and Alinezhad, 2010: 169).

Rubino (2016) who discusses reduplication by regarding the aspects like form, function, and distribution in this process both in full and partial manners and tries to manifest the changes occurred at the results of reduplication process by bringing examples from many languages, emphasizes that most areas of the world do have languages that employ reduplication productively for quite diverse purposes and with varying degrees of iconicity. 
Other researches by Regier (1998), Zhang (1999), Tsao (2001), Conradie (2003), Lakoff \&Johnson (1980), Hiragara (1994), Spenser (1991), Aronoff (1974), Marantz (1982), Ghomeyshi et al. (2006) are also important works on reduplication and the significant views about this morphological process have been presented by Inklas(2006), Moravesik(1970) and Inklas\&Zoll (2005).

\section{REDUPLICATION IN KURDISH LANGUAGE RESEARCHES}

\section{Kurdish Langauge}

Kurdish is a cover term for a bundle of closely-related West Iranian dialects spoken across a large contiguous area spanning the intersection of Turkey, Iraq and Iran. Smaller communities of Kurds also live in Syria, Armenia and Azerbaijan, and a sizeable exile community (at least 700,000) now live in Western Europe. Estimates of the total number of Kurdish speakers vary wildly, generally between 15 and 25 million. In terms of numbers of speakers and degree of standardization, the two most important Kurdish dialects are Sorani (or Central Kurdish) and Kurmanji (or Northern Kurdish). Home scholars, e.g. KRPYENBROEx (1992), have pointed out that the structural differences between sorani and Kurmanji could justify treating them as two distinct languages. However, the traditional terminology, and the one favored by most native speakers, is to consider them as dialects of a superordinate unit “Kurdish”(Haig \& Matras, 2002: 2).

\section{Research about reduplication process in Kurdish language:}

Since the uses of double terms or dual construction (repeat) are very common in the conversations in Kurdish language, this language phenomenon are always interested by the Kurdish language researchers. In this regard, in summary the research that has been done on this process is pointed out:

Rashid (1977) in his research entitled "pairs of words in Kurdish language", offered comments and points about individual data that he considered them as special features of Kurdish language and he called them as evidence that show the richness and antiquity of the language, Galali (2004) also in his book "word pairs" takes advantage of descriptive-analytic process and he sees this construction in terms of different and new perspective and he investigated reduplication almost in all aspects (morphologically, phonologically, syntactically and semantically). Salam (1977), in a writing under the name (pair words or peer-word) criticized Rashid comments and he expresses his idea the same way by mentioning several examples that he called them as peer-word, and he mentioned that in a series of these compounds first word has meaning and second word directly, often, is without meaning while in words like (lat-u-lavaz), (cher-u-chaw), (mosht-u-mir) and (kat-u-per) that are related by infix " $u$ ", the first word has no meaning and the second one is meaningful. Marif (1979) in one of section of his "morphology" book has some references to reduplications and that how they are made and how infixes ("u", "e", "bê") are used to make these compounds and he addresses it in terms of morphological view. Basir (1979) referred to this issue as Kurdish language morphologically belongs to continuous languages and a large 
part of its vocabulary are combined and based on the combination of two meaningful words refer to data that are joined by infixes such as (e) like "qîre qîr", "minge ming", "denge deng".

Fakhri (1983) considers word pairs as a part of the overall process of reduplication that mutually combine to be paired in terms of appearance, or take a single meaning for content. She divided pair words in terms of the structure and meaning into two different categories that in each section she has expressed their different categories and then she offered a comparative study for reduplication between the Kurdish and Arabic and he believes that a part of pair words have meaning and phonological similarity and some other showed that second word is added according to the morphological form of first word. Maarouf (1989) in a writing under the title "limited repetition" stated limited aspects of reduplication and he considered that as a part of process and he referred to a number of rules for the process, among them, they are not separated by other word and they will not be back and forth and both elements have identical semantic and syntactic features and he also referred to this issue that these compound words can be used as noun, adjective and adverb in a sentence. He has just looked in term of syntax to this issue and he only talks about compound words that are interconnected by infix (u). Feizizadeh (1968) in his book entitled "culture of double words in Kurdish language" divided this combination of words in terms of semantic into several categories, and he selected a name for each category: the first part are those reduplicated words that in authors' viewpoint are mentioned automatically one by one, such as "ga-ugoul". The second part of author work in this book is related to the words in which nouns, either before or after, have independent and harmonic function, such as "Bon-u- Beram" and "Ber-u-pișt". The third part refers to terms that meaningful or meaningless work as dependent and followed like "Rêga-u- Ban" that have uncoordinated relationship with dependent or "Befr-u- Mefr" that are made by using "M" instead of the first letter of foundation and adding " $u$ " between the two parts and the second part is null. Rasekh mahanad and Mohammadi Rad (2014) also, in a study, address to formal and semantic aspects of reduplication in Kurdish language, dialect of Sorani, and they have compared it with duplication construction in Persian language. They have done their research according to view of Moravesik (1978) and concluded that in terms of morphological features, duplication construction is alike in Kurdish and Persian languages, but in terms of phonological construction, there are differences in both languages and in semantic features, frequency of quantity concept is more in both languages.

\section{THE RESEARCH SIGNIFICANCE:}

Researchers believe that investigation on reduplication which is a sort of wordformation, help linguists to find about terms that are independent and since they have no function out of the construction of reduplication it may be possible to discover where they come from or what changes they experience. This kind of study refers us to root and beginning of word that sometimes cause to rescue words. Kurdish language is among languages in which reduplication process work as a relatively independent method and they have special features. In conversation and communication in Kurdish language, reduplication is very useful and for this reason it is very interested by researchers. 


\section{METHODOLOGY}

This study is a descriptive research. It was tried to be brought a comprehensive description of reduplication patterns and its categorizations. Research data, according to native views, language intuition of authors and also referring to books and cultures in which reduplicated words are gathered either particularly or in conjunction with other morphological and syntactic issues. Analysis and review of data is also done by providing semantic and lexical evidences.

\section{DISCUSSION}

As noted above, there are two kinds of full and partial main process in reduplication process, each with varied patterns. Full one (doubling or redoubling in the framework of phonological copying theory and morphological doubling) is described. In a group of structures the same words repeated and no combined element is used between two morphemes, they can be two versions of verb root. Such reduplications imply to continuity, increase and the intensity. They sometimes signify the counting and even reduction. In terms of phonological and morphological, second element is like iteration of first element and the emphasis is on its meaning. Although two morphemes are exactly the same, but according to Bollinger (1968), first morpheme is base and second morpheme is a repeated element. This way of repeating that Galali (2004) called reduplication or doubling words can be existed in all languages and no especial and different process is viewed for it in Kurdish language. In fact, this method of reduplication is called phonological copying. Repeated morpheme can be noun, adjective, adverb or verb base. In this method nothing is reduced or added.

According to Galali, complete iteration is displayed as follows:

$$
\mathrm{C} \mathrm{VC}+\mathrm{CVC}
$$

If the final syllable ends to vowels, compound has the following structure

$$
\begin{aligned}
& \text { C V C V C V + C V C V C V ... } \\
& \text { [jar] ' once' — [jarjar] 'sometimes' (jar- jar) } \\
& \text { [helat] 'run' - [helathelat] ' running and runing' (run- run) } \\
& \text { [wired] ' alittle'-[ wirdewirde] 'little by little' (wired- wired) } \\
& \text { [sûr] 'red'- - [sûrsûr] ' very clearly' (sur-sur) } \\
& \text { [tav] ' time' - [ [tav tav] 'occasionally' (tav-tav) } \\
& \text { [dir] ' rip' [dirdir] riping and tearing' (dir-dir) }
\end{aligned}
$$

In south African English, 'now-now' means ' immediately' (whereas an ordinary 'now' can also mean 'somewhat later' ). 
There is another way of redoubling that it seems to be certain for Kurdish language in this way that the last voice of the second term can be eliminated and it happens in vowels morphemes. In this compound, coordination takes place from right to left. This reduplication is partial.

There are some reduplication in which parts are connected by (e) but it has an Izafe e. While in the combination of "Lore Lor" (e) belongs to the word itself that in the process of second partial repeat (e) is lost but in "Denge Deng", (e) is an Izafe elemet.

According to Galali, complete iteration is displayed as follows:

$$
\mathrm{C} \mathrm{VC}+\mathrm{CVC}
$$

If the final syllable ends to vowels, compound has the following structure

$$
\mathrm{CVC}+\underline{\mathrm{V}}+\mathrm{CV} \mathrm{C}
$$

But if iteration happens for a morpheme partially, according to the same source syntax is as follows:

$$
\text { Ø C V C + V C V C }
$$

[trûke]'shiny'—[trûketrûk] 'shining continually' (trûke - trûk-Ø)

[haze] ' singing of water on the fire before boiling' — [hazehaz] ' singing' ( haze- haz-Ø)

[ jirîve] ' shining the stars or the song of sparrows' - [ jirîvejirv] ' shining singing'(jirîvejirîv- Ø)

[deng] 'sound' — [dengedeng] ' buzz or noise' (deng- e- deng)

In a category of the reduplication process, morphemes belonging to classes of noun, adjective or adverb are connected by infix (BE) and they show accuracy, emphasis and continuity and also counting or in some other cases compaction and increase. This category of patterns according to Rafiee et al., (2015) about reduplication in Farsi language pointed out that they are explainable in terms of morphological doubling theory, i.e. due to similarity of meaning in both sides of affixes, addition of this construct can be as a semantic evidence confirming similarity in meaning in morphological doubling theory.

[sal] ' year' — [ salbesal] ' year by year' ( sal- be - sal)

[mal] ' house' - [ malbemal] 'from this house to another' ( mal- be - mal)

[gor] ' grave' — [ gorbegor] ' grave to grave' ( gor- be - gor)

[yek] 'one' — [yekbeyek] ' one by one' ( yek- be- yek) 
Full reduplication by using the link elements such as relative words or prepositions and conjunctions or infixes such as ( $u, a w$, leser) is such a way in which a structure that one infix (aw) is used shows congestion, diversity and contrast and morphemes induce such relations simultaneously and together.

[ling] 'one portion of a pair' — [ lingawling] ' one side of a pair' ( ling-aw-ling)

[pișt] ' back' - [ piștawpișt] ' going backwards' (pișt-aw-pișt)

(leser) also shows increase and continuity. "xak leser xak defroshê" (someone who sells his land successively) this shows that he has much land and also shows repeat in selling but it is different in some compounds, for example, "dest leser dest damenê" ( do not stop) (be active). Do not linger.

[xak] ' land' — [xakleserxak] ' lands one by one' ( xak-leser- xak)

[dest] 'hand' — [destleserdest] ' stopping' ( dest- leser- dest)

In another example of partial reduplication in which reduplication takes place in accordance with phonological conditions of the first morpheme, we have two components with formal relationship with each other as seen in several ways: some have shared first sound, they link with a connection word such as "u"(and) together. Such as "qap v qaçaq", "lêre u levê", "dem u didan", "seppi u sol". Others share their last or more sounds, such as "șil u mil ", "xir u pir", "şax u dax", "jar v bar".

$$
\begin{aligned}
& \text { [șil] u [șewêq] 'loose' and(Ø) — [șilușewêq] 'flimsy' (șil-u-șewêq) } \\
& \text { [qap] u [qaçaq] 'dish' and (Ø) — [qapuqaçaq] ' dishes' (qap-u-qaçaq) } \\
& \text { [zibl] u [ zal] ' rubbish' and (Ø) [ zibluzal] ' rubbishes' (zibl-u-zal) } \\
& \text { [reș] u[ rût] ' black and naked' — [reșurût] ' poor' (reș- u- rût) }
\end{aligned}
$$

Sometimes the second word shows the outcome and effect of the first morpheme. Sometimes these two words may have a phonetic similarity. In fact, the second component indicates the outcome and impact of first component. "sardusir", "gurutin", "germugur"

[sard] $\mathrm{u}[\mathrm{sir}]$ ' cold and numb' — [sardusir] (insensitive or emotionless and also cold and numb) (sard-u-sir)

[germ] u [gur] ' hot and flush' — [ germugur] ' hot and warmly' (germ-u-gur) 
It is also seen in other samples that two components alone have no meaning but in combination they make a single meaning. But in most cases first component has meaning and second component has no meaning and vice versa, the latter is less frequent. "kelupel" both has no meaning but together mean furniture. The first part of "nermunol" means gentleness or softness and it can be used in other compounds or by itself while "nol" is meaningless and it is only used with "nerm". In "teputoz", Hajar(2000) mentions one of its meanings as "Toz" (dust) and the word "Toz" has separately many applications but "tep" alone in speech and writing has no similar meaning as in combination with "toz", and if it is used, it is likely have other meanings, such as "lazy".

[kel] u[ pel] ' $\varnothing$ and $\varnothing$ ' — [kelupel] ' furniture' (kel-u-pel)

Another reduplication pattern is a reflection or an echo that is very common and in other languages such as English and Persian many examples is seen. In Kurdish, reflection reduplication cause to make a correspondence chain combination in a way that " $\mathrm{M}$ " is added to the first component of second that is reflection of first component. In this type of reduplication, in many cases second component has no meaning.

Kurdish: "dar u mar", bax u max", "Jil u mil”,

In Persian also "Topol Mopol" is used without mentioning "u" between two morphemes

As in English, we have words like

Namby-pamby, hugger- mugger, culture-vulture, Bow wow.

[dar] u [mar] 'tree' and [Ø] — [darumar] ' trees and things like that' [dar-umar]

[bax] u [max] ' garden' and [Ø] — [ baxumax] ' garden and things like that ( bax $-\mathbf{u}-\mathbf{m a x})$

In another form of repetition, two components are linked with $(\mathrm{u})$ and often both components are synonyms, but they are completely different in appearance. Galali (2004: 3640) believes that in some cases these compounds may be confused with the word-groups. He believes that word-groups are separate and they are not included within the framework of definitions and theories that related to reduplication. He also believes that there is a horizontal -semantic connection between this kind of idioms such as the relationship between "top' (ball), "pê" (foot) and "hawiștin" (throw).

In overall, a number of idioms are used in pairs so that they have not experienced the reduplication process or they are not similar phonologically, but they are two separate morphemes that have semantic relations or can play a role in strengthening of meaning 
together. As Inclass and Zul (2005) state it cannot be justified by resorting to theories such as phonological copying, but their review only takes place in the framework of morphological doubling.

There are also some examples in which two morphemes are opposite. These examples usually have no relation in terms of phonological form, too, and their relationship is only created through meaning. In most cases of these categories each part of compound have their own independent meaning. If they are synonym, they show increase or emphasis or new meaning is mad at the result of compounding while if two components have contrast in meaning they indicate on an overall theme. For example, life and death, or hand and foot, shoulder and scapula, short and summary, etc. Feizizadeh(1968) called this type of construction as an uncoordinated relationship in which function and respective are not matched phonologically. He also placed compounds in which the first sound of their second part changes to $(\mathrm{m})$. The second part is semantically null. This kind of reduplication is reflective reduplication that we have already mentioned.

[jil] u [ berg] ' clothes' and 'clothes' — [jiluberg] 'clothes' (jil- u- berg)

[pê] u [ qedem] ' desert' and' step' — [ pêuqedem] ' presage' (pê- u - qedem)

[tar] u [ dinbek] ' Tar' and 'Tombak' - [ tarudimbek] ' two musical instruments used together' (tar- u- dimbek)

[tal] u [ siwêrî] ' bitter' and 'salty' — [ talusiwêri] ' life hardships' (tal- u- siwêrî)

\section{Incompatibility}

Some numbers of reduplication are not compatible. It means they are opposite are synonym but their meanings attached to one of its parts. For example "pirupouch" (full and empty) that means "nothing" at the same time " hichupouch"( nothing and empty) also means " nothing". They are called incompatible reduplications.

\section{CONCLUSION}

According to the arguments and data we can outline some rules and express: on the contrary of two components of a word group, the components of reduplication do not accept definite, indefinite and plural signs if it is a noun. The number of morphemes in reduplication in Kurdish language is not usually more than two morphemes. It is not easy to change the place of morphemes forming reduplication composition. No other morpheme can be placed between two morphemes because the subjacency principle (Haegeman, 1992:445) is violated and because reduplication process changes them into a constituent. Interrogative words or demonstratives are not come between these two morphemes unless they come after compound or before that. Semantic relationship between the two morphemes of reduplication is a limited one. None of the parts of reduplication constituent are used alone and if they come alone they would not have the same meaning that have in the combination. In terms of phonological 
construction, the difference between reduplication and word-groups is that both morphemes in reduplication have a unit stress.

\section{REFERENCES}

Bolinger D, 1968. Aspects of language, New York: Harcout, Brace and word.

David N. MacKenzie. 1961. Kurdish Dialect Studies. Oxford University Press.

Feyzizadeh, Taha, 1988. Kurdish Binary words dictionary. Orumieh: Literature and culture center press.

Galali, Kosar Aziz Ahmad, 2004.Doubled words in Kurdish, Hewler: Aras Publication, No 437.

Ghaniabadi, S., Ghomeshi, J., \& Sadat-Tehrani, N. (2006). Reduplication in Persian: A morphological doubling approach. In Proceedings of the 2006 Annual Conference of Canadian Linguistic Association (pp. 1-15).

Ghaniabadi, Saeed. 2005. Echo reduplication in colloquial Persian: an OT Analysis. Linguistic Analysis 24:175-217.

Goeffrey Haig and Yaron Matras. 2002. Kurdish Linguistics: A Brief Overview. Sprachtypologie und Universalienforschung / Language Typology and Universals, 55(1).

Golfam, Arsalan and QhomSheie, Gholamreza Meheyedin, 2011.The iconicity of Reduplicative constructions in Persian, Tehran: Language and contrastive researches magazine, p153-172.

Gonda, J. 1950. "The functions of word duplication in Indonesian languages". In Lingua 2: 170-197.

Haegeman, L.(1992). Introdution to Government \& Binding Theory. Oxford: Blackwell.

Haas, Mary. 1942. “Types of Reduplication in Thai”. In Studies in Linguistics 1: 1-6

Hestermann, Ferdinand (1915). Die Repetition in der Sere,rsprache von Senegambien. Zeitschrift der Deutschen MorgenlaXndischen Gesellschaft 69. 107-112.

Inkelas, Sharon and Cheryl Zoll. 2000. Reduplication as Morphological Doubling. MS, UC Berkeley and MIT.

Inkelas, Sharon and Cheryl Zoll. 2005. Reduplication. Cambridge: Cambridge University Press

Inlelas, Sharon. 2008. The dual theory of reduplication. Linguistics 46:351-402. 2008 
Lai, Huei-ling 2006. Iconic Coding of conceptualization: Hakka Reduplicative construction. National Chengchi University, Language and Linguistics 7.2 483-499.

LOPEZ, Cecillio. 1950. REDUPLICATION IN TAGALOG Bijdragen tot de Taal-, Land-en Volkenkunde Deel 106, 2de Afl. (1950), pp. 151-311

Katamba F. 1993. Morphology, Houndsmill Basingstake, London: Macmillan press.

Kauffman, Charles. A, 2015. Reduplication reflects uniqueness and innovation in language, thought and culture. Omniglot - Online Encyclopedia of Writing Systems \& Languages (Publisher Simon Ager).

Khanjan, Alireza and Batool, Alinezahd, 2010. A morphological doubling Approach to Full Reduplication in Persian, Helsinki. SKY Journal of Linguistics Vol 23:2010, 169- 198.

Marantz, Alec. 1982. Re reduplication. Linguistic Inquiry 13:483-545.

McCarthy, John and Alan Prince. 1995. Faithfulness and reduplicative identity. In J. N. Beckman, L. Walsh Dickey and S. Urbanczyk, eds., UMOP: Papers in Optimality Theory 18, 249-384

MC carus D, 1959. A Kurdish grammar, Washington.

Moravcik, Edith. 1978. Reduplicative constructions. In (ed) J. Greenberg, Universals of human language, vol. 3: Word Structure. Stanford: Stanford University Press, 297- 334.

Novotna, Jana 2000. Reduplication in Swahili. AAP 64(2000): Swahili Forum VII 57-73

Rezayati, M. Kishekhaleh \& Soltani, Behrouz, 2015. A Study on the Reduplication Process in Persian Language from Vocabulary Building, Grammar and Semantics Points of View (Text in Persian) Pages 81-112, Mashad: Literary Study Magazine, Ferdowsi University of Mashhad.

Sharafkandi, Abdolrahman (Hajar), 2000. Kurdish - Persian dictionary. Tehran: Soroush Press.

Tkaczyk, Bartosz (2005) Clone fixation, i.e. reduplicative process and its representations. Presentation given at the 3rd Athens Postgraduate Conference in Linguistics (APCiL) in Athens, April 9-10, 2005.

Wheeler M. Thackston. 2006a. Kurmanji Kurdish: A Reference Grammar with Selected Readings. Harvard University.

Wheeler M. Thackston. 2006b. Sorani Kurdish: A Reference Grammar with Selected Readings. Harvard University.

YU, Alan C. L.. Two Patterns of Reduplication in Washo. Annual Meeting of the Berkeley Linguistics Society, [S.1.], p. 365-376, dec. 2008. ISSN 2377-1666. Available at: 
<http://journals.linguisticsociety.org/proceedings/index.php/BLS/article/view/3583>. Date accessed: 30 aug. 2016. doi:http://dx.doi.org/10.3765/bls.v34i1.3583. 